\title{
Optimal Employee Ownership Contracts under Ambiguity Aversion
}

\author{
Nicolas AUBERT ${ }^{1}$ \\ Hachmi BEN AMEUR ${ }^{2}$ \\ Guillaume GARNOTEL ${ }^{3}$ \\ Jean-Luc PRIGENT ${ }^{4}$
}

\begin{abstract}
The aim of this paper is to compute and describe the conditions of an optimal employee ownership contract between an employer and an ambiguity-averse employee. We then introduce ambiguity aversion in the baseline model of Aubert et al (2014) using the multiple prior preferences of Gilboa and Schmeidler (1989) and its extension proposed by Maccheroni et al (2006). This model offers solutions that reconcile labor and financial economics and behavioral economics research findings on employee ownership. The paper focuses on the most common situation where employee ownership has a positive impact on corporate performance, but can also be used as an entrenchment mechanism. We determine the optimal company stock contribution, which corresponds to a perfect subgame Nash equilibrium in the ambiguity framework. Using the framework of Gilboa and Schmeidler's (1989), we show that the optimal ownership contract is respectively increasing with respect to the lower bound of the return expectation in the case of a high level of effort, and decreasing with respect to the upper bound of the return expectation in the case of a low level of effort. In the framework of Maccheroni et al (2006), we prove that if aversion to ambiguity is sufficiently high, then we find the same behavior as in the case of no ambiguity. ${ }^{5}$
\end{abstract}

JEL classification: G11, G32, G34, J33.

\footnotetext{
${ }^{1}$ Aix Marseille Univ, CERGAM, IAE Aix-Marseille, Aix-en-Provence, France. niaubert@gmail.com

${ }^{2}$ Inseec Business School, 27 rue claude Vellefaux 75010 Paris. hbenameur@groupeinseec.com

${ }^{3}$ Inseec Business School, ggarnotel@ groupeinseec.com.

${ }^{4}$ University of Cergy-Pontoise, Thema, Cergy-Pontoise: France, jean-luc.prigent@u-cergy.fr

${ }^{5} \mathrm{We}$ would like to thank the editor Professor Wilson, Professor Jawadi and an anonymous referee for their helpful comments and suggestions.
} 


\section{Introduction}

Employee stock ownership is when employees own shares of the company for whom they work. Employee ownership is a major part of shared capitalism, with 14 million employee owners in the US in $2014 .{ }^{6}$ Shared capitalism refers to "schemes that tie worker pay or wealth to their own workplace performance, whether at the level of the workgroup, institution, or company" (Kruse et al, 2010; p. 5). Shared capitalism was extended to a wider public in 2015 by former members of the US government ${ }^{7}$ who suggested promoting inclusive prosperity. The main argument of shared capitalism is that sharing wealth helps to stimulate growth. By participating in the wealth of the company they work for, employees work more and better, which subsequently improves corporate performance and stimulates economic growth. The idea was initially promoted by Martin Weiztman to fight stagflation in the 1980s (Weitzman, 1984). Shared capitalism resurfaced after 2008 as a solution to share wealth, and fight poverty and inequality (Kruse et al, 2010). Blasi et al (2013) even argue that shared capitalism has always been a major component of the US economy, promoted by the founding fathers, and one of the reasons for America's economic growth since the $19^{\text {th }}$ century. However, employee stock ownership outcomes remain debatable.

The decision to introduce and develop employee ownership generally lies with management. When offered as an investment option by the employer, the employees can decide whether or not they want to buy the company stocks on offer. Consequently, employee ownership can be analyzed as a contract between the employer and the employee. This paper investigates the characteristics of an employee ownership contract when the employee is ambiguity averse. Ambiguity aversion or uncertainty aversion refers to the preference for known risks over unknown risks. More technically, the presence of ambiguity reflects the non-uniqueness of prior probabilities over sets of states. Rather than having in mind a unique probability to determine expected utility, the agent faces a whole set of possible probabilities, or so-called prior probabilities.

The present paper also converges the findings of three different fields of economics, since labor, financial and behavioral economics have investigated employee ownership separately to date. Labor and financial economics have focused on the consequences of employee ownership, while behavioral economics has documented the causes of employee ownership. Labor economics and industrial relations establish a link between employee ownership and enhanced corporate performance. Financial economics on the other hand, tends to show that employee ownership damages corporate governance. Behavioral economics documents many cognitive biases, leading employees to overinvest in their company stocks, but has never included ambiguity aversion as one of them. The presence of positive and negative effects suggests an optimal level of employee

\footnotetext{
${ }^{6}$ According to the National Center for Employee Ownership (https://www.nceo.org/articles/statistical-profileemployee-ownership accessed on December 2016).

7 See Peter R. Orszag Bloomberg's article commenting on a report from the Center for American Progress Commission on Inclusive Prosperity, co-chaired by Lawrence Summers (https://www.bloomberg.com/view/articles/2015-01-20/in-state-of-the-union-obama-should-push-to-give-workers-astake accessed on December 2016). The report on Inclusive Prosperity can be accessed at: https://cdn.americanprogress.org/wp-content/uploads/2015/01/IPC-PDF-U.S.appendix.pdf
} 
ownership that stimulates corporate performance without harming corporate governance. This level suits the behavioral preferences of the employee in terms of ambiguity aversion. Unlike much of the prior literature, our model does not consider employees' and employers' behavior as being separate from their environment. Instead, we consider interactions within the workplace by illustrating strategic interactions between the employer and the employee.

The main conclusions of labor economics and industrial relations' regarding employee ownership is that it improves corporate performance (called 'performance motive' hereafter). Performance motive relies on the positive effects of employee ownership within the workplace in terms of cooperation, mutual monitoring, staff turnover and absenteeism. The meta-analysis by O'Boyle et al (2016) reviewed 102 samples representing 56,984 firms in different countries. They reported an overall positive and significant relationship between employee ownership and firm performance measured in terms of efficiency or growth. Several chapters of the book by Kruse et al (2010) also point to evidence of the positive relationship between employee ownership workplace outcomes and corporate performance based on survey and archival data collected on a sample of 40,000 employees representative of the US workforce. The shared capitalism survey items are now included in the General social survey of the National opinion research center. ${ }^{8}$

Financial economics often regards employee ownership as a management entrenchment tool ('entrenchment motive' hereafter). Schleifer and Vishny (1989) claim that managers entrench themselves in their position when they counter the financial market disciplinary forces " $b y$ making themselves valuable to shareholders and costly to replace" (p. 123). Since employees and managers are natural allies against hostile takeovers (Pagano and Volpin, 2005; p. 841), managers prefer to place shares in the friendly hands of employees (Benartzi et al, 2007). The negative effect of employee ownership on corporate governance is well documented empirically (Beatty, 1995; Chaplinsky and Niehaus, 1994; Park and Song, 1995; Chang, 1990; Chang and Mayers, 1992; Conte et al, 1996). Rauh (2006) and Brown et al (2006) also concluded more recently that employee ownership has a deterrent effect on the likelihood of a takeover. Behavioral economics began investigating why employees invested in their company's stocks for their pension plan following the dotcom crisis when thousands of employees lost their jobs and savings. Most of the literature on household finance (Guiso and Sodini, 2013) and behavioral finance (Barber and Odean, 2013) examined retail investment through the data on pension plan participants. As reported by Guiso and Sodini (2013), the concentration of US citizens' pension wealth in employer's stocks is noteworthy and of some concern to the public authorities. According to Benartzi et al (2007), investment in employer's stock comes at a high cost for both employees and employers. Previous research suggests that employees' investment in their company stock is a consequence of cognitive biases such as excessive extrapolation of past returns and endorsement (Benartzi, 2001), loyalty and familiarity (Cohen, 2009; Huberman, 2001), framing effect (Benartzi and Thaler, 1999, 2002), risk myopia (Mitchell and Utkus, 2003), disposition effect (Choi et al, 2004), and default heuristics (Madrian and Shea, 2001).

To the best of our knowledge, no study to date has investigated ambiguity aversion, either theoretically or empirically. However, ambiguity aversion affects less sophisticated individual investors like employees who are not always able to infer the probability distribution of stock returns when they are offered an investment in their employer's stock. Ambiguity was first

\footnotetext{
${ }^{8}$ http://www.norc.org/research/projects/pages/general-social-survey.aspx
} 
documented by Ellsberg (1961). Charness and Gneezy (2010) conducted an experimental comparison that considers three biases well known in the behavioral finance literature: ambiguity aversion, the illusion of control and myopic loss aversion. Gilboa and Schmeidler (1989) suggest accommodating ambiguity within economic decision-making, and assume that in the presence of ambiguity, individuals cannot identify a single probability distribution over states of nature. They thus consider multiple probability distributions and then evaluate their choices according to the worst probability distribution for that choice. This approach is based on multiple priors. The decision model is called "maxmin expected utility" (MEU hereafter) whose beliefs are given by a set of probabilities, with decisions made to maximize the minimal expected utility of the act chosen. Our model adopts this approach.

The model postulates that employers' financial contributions are a means to stimulate employee ownership ${ }^{9}$ and reveal the manager's type. From this standpoint, the prevailing management type is supposedly revealed by the amount of company stock that management decides to grant to its employees. Rauh (2006) claims that strategic corporate control is one of the main reasons why managers encourage employees to hold company stock in their defined contribution pension accounts. The monetary contribution given by managers to their employees plays a major role. The forms of employer monetary contributions depend on the context in which they are granted to the employee: an Employee stock purchase plan (ESPP), defined contribution plans like the 401(k) or Employee stock ownership plans (ESOP). Within an ESPP, a discount is offered on the stock price. Managers can also help to boost employee ownership through an ESOP. ESOPs frequently give employees company stocks, often with no up-front cost to the employees. In a 401(k) style company-based savings plan with several investment options, matching contributions in company stocks are offered by the employer. This means that additional company stocks are granted to employees when they choose to invest in their employer's stocks. We extend the conclusions of the Aubert et al (2014) model by introducing ambiguity aversion. In the context of standard utility theory, Aubert et al (2014) considered that a firm's management type is revealed by the way management contributes financially to the development of employee ownership. Good managers stimulate employee ownership because they want to boost corporate performance (performance motive), whereas bad managers encourage it because it can help them to retain their position (entrenchment motive). In the ambiguity theory framework, we extend the previous contribution by providing a general finding about the existence of a perfect subgame Nash equilibrium, taking ambiguity into account. We propose a sequential game where a riskneutral manager grants company stock to risk-averse employees, while both face ambiguity. ${ }^{10}$ In the framework of Gilboa and Schmeidler's (1989), we demonstrate that the optimal ownership contract is respectively increasing with respect to the lower bound of the return expectation in the case of a high level of effort, and decreasing with respect to the upper bound of the return expectation in the case of a low level of effort. In the framework of Maccheroni et al (2006), we prove that if the ambiguity aversion is sufficiently high, then we find the same behavior as in the scenario without ambiguity.

The remainder of the paper is organized as follows. Section 2 presents the model setup and the

\footnotetext{
${ }^{9}$ Benartzi (2001), Holden and Van Derhei (2001), Brown et al (2006) and Purcell (2003) found that concentration in company stock is significantly higher in companies where matching contributions in company stocks are offered.

${ }^{10}$ Risk-neutrality is the standard assumption about managers' behavior in both the microeconomic and corporate finance literature. Thus, we make this assumption while introducing risk aversion for employees. The same setup is followed by Aubert et al (2014).
} 
optimal employee ownership contract under ambiguity aversion. Section 3 concludes. Proof is provided in the appendix

\section{Optimal employee ownership under ambiguity}

In this section, we present the model setup (subsection 2.1) and we derive the optimal employee ownership contract characteristics under ambiguity aversion (section 2.2). In the second subsection, we develop the conditions under which an equilibrium exists that satisfies the employees' and the managers' preferences.

\subsection{Model setup}

Our model relies on the MEU approach, which is more flexible than the standard expected utility criterion. Furthermore, it provides a distinction between risk and ambiguity, and can capture preference with ambiguity aversion. Maccheroni et al (2006) characterize preferences under ambiguity by introducing both a utility function $U$ defined on outcomes and an ambiguity index $C$ defined on a set $\Delta$ of probabilities regarding the random events. The latter set is viewed as the individual's set of priors. Ambiguity is associated with the multiplicity of priors. Thus, they consider the following representation of preferences:

For all random variables $X$ and $Y$ which represent results or consequences, and with values in $[-M, M]$, we have:

$$
\begin{gathered}
X \geq Y \Leftrightarrow \\
\operatorname{Min}_{p \in \Delta} \int U(X) d P+C(P) \geq \operatorname{Min}_{p \in \Delta} \int U(Y) d P+C(P)
\end{gathered}
$$

The function $U$ corresponds to decision risk attitude. Index $C$ represents individual attitude towards ambiguity. This representation of preferences includes both the multiple priors' preferences of Gilboa and Schmeidler (1989) and the multiplier preferences of Hansen and Sargent (2000, 2001). The MEU criterion of Gilboa and Schmeidler (1989) corresponds to the case where $C=0$ and $\Delta$ is a convex set. Hansen and Sargent $(2000,2001)$ propose a robust preference approach where individuals are uncertain about their modeling of random events. The ranking of decisions is based on:

$$
\begin{gathered}
X \geq Y \Leftrightarrow \\
\operatorname{Min}_{p \in \Delta} \int U(X) d P+\xi R(P, Q) \geq \operatorname{Min}_{p \in \Delta} \int U(Y) d P+\xi R(P, Q)
\end{gathered}
$$

where $R(P, Q)$ denotes relative entropy with respect to the given probability distribution $Q{ }^{11}$

\footnotetext{
${ }^{11}$ Recall that the relative entropy of the probability distribution $P$ with respect to the probability distribution $Q$ is defined by $R(P, Q)=E_{P}\left[\log \left(\frac{d P}{d Q}\right)\right]$. Note that $R(Q, Q)=0$. Relative entropy has been introduced in both the probability and information theories to measure the difference between probability distributions $P$ and $Q$. It
} 
This kind of preference is known as a multiplier preference. Parameter $\xi$ represents the weight individuals give to the possibility that due to the lack of information, $P$ is not the appropriate probability distribution. Maccheroni et al (2006) establish theoretical connections between the two approaches. For a given set $\Delta$, the lower $C$, the higher the ambiguity aversion. MEU captures an extreme form of ambiguity aversion in the sense that the decision-maker bases his or her decisions on worst-case scenarios.

We consider three stages involving a risk-neutral manager and a risk-averse employee. The manager's wealth is fully invested in company stock but the resulting stake is insufficient to ward off a takeover attempt. We assume the manager holds a given amount of company stock at the beginning of the game. These features allow us to analyze the game without explicitly including the other shareholders as players. The employee is representative of all company employees.

There are two types of managers: good $(G)$ managers and bad managers $(B)$ with $k=\{G, B\}$. At $t=0$, the manager's type is determined. Only the manager knows this information. The employee does not observe the manager's type and has an a priori probability distribution $P_{0}$ with regard to perception of the manager's type. Thus, $P_{0}(G)=p_{0}$ is the probability that the manager is good and $P_{0}(B)=1-p_{0}$ is the probability that the manager is bad with $0<P_{0}<1$. The manager's type affects the rate of return on company stock. Good managers are more likely to perform better than bad managers. This is denoted by index $k$ of the rate of return.

At $t=1$, the manager designs a compensation scheme aimed at motivating the employee to make more effort. The compensation scheme we investigate only consists of company stock. $c$ is the level of employee ownership. We thus consider a setup where the manager has to decide whether to offer company stock to the employee and the amount of stock to offer.

At $t=2$, the employee evaluates the compensation scheme and chooses the level of effort. The employee's effort can either be high ( $H$ ) or low $(L)$ with $j=\{H, L\}$. The level of effort affects the rate of return on company stock.

The rate of return on company stock is given by $R+M^{j, k}$, where $R$ is a random variable with a zero mean, volatility $\sigma$ and density $f(r)$. It represents the stochastic part of the rate of return. The random variable $M^{j, k}$ is the excess return of the company with mean $\mu^{j, k}$, and takes different values according to manager's type $k$ and employee's effort $j$. Random variables $R$ and $M^{j, k}$ are independent. ${ }^{12}$ The possible values of $\mu^{j, k}$ are: $\mu^{L, B}, \mu^{L, G}, \mu^{H, B}$, and $\mu^{H, G}$.

Ceteris paribus, we assume that a better manager or more employee effort increases the rate of

corresponds to the Kullback-Leibler divergence from $Q$ to $P$ and quantifies the information gain when we revise beliefs from the prior probability distribution $Q$ to the posterior probability distribution $P$.

${ }^{12}$ The independence assumption can be relaxed for the manager since the latter is risk-neutral, which implies that the manager's expected utility can be computed without any assumption about the joint distribution of $R$ and $M^{j, k}$. However, we must use this joint law to compute the employee's expected utility. Thus, given $R$, we have to introduce specific multipriors to describe ambiguity with respect to the conditional distributions of $M^{j, k}$. To avoid this additional and cumbersome complexity, we assume that $R$ and $M^{j, k}$ are independent. 
return on the company stock. We then consider the rational conditions $\mu^{L, B} \leq \operatorname{Min}\left(\mu^{L, G}, \mu^{H, B}\right)$ and $\mu^{H, G} \geq \operatorname{Max}\left(\mu^{L, G}, \mu^{H, B}\right)$.

In what follows, we model ambiguity for both the manager and the employee as in Maccheroni et al (2006). This means that there are two sets of multipriors, $\Pi_{R, \mu^{j, k, m}}$ and $\Pi_{R, \mu^{j, k, e}}$ corresponding respectively to the manager and the employee. These sets respectively model the ambiguity about the choice of probabilities $P_{R, \mu^{j, k, m}}$ and $P_{R, \mu^{j, k, e}}$ to evaluate the expectation of respective utilities of both the agents. There are also two ambiguity indices, $C_{m}$ and $C_{e}$. The latter functions are assumed to satisfy the conditions defined in Maccheroni et al (2006).

We make the following assumption:

ASSUMPTION 1 Both sets of multipriors $\Delta_{m}=\Pi_{R, \mu^{j, k, m}}$ and $\Delta_{e}=\Pi_{R, \mu^{j, k, e}}$ are compact.

REMARK 1 The previous assumption is satisfied when, for example, the minimization of expected utilities on the given set $\Delta_{m}\left(\right.$ or $\left.\Delta_{e}\right)$ is equivalent to the minimization of a given set of parameters. This is true when the distribution of $M^{j, k, l}$ is parametrized with parameters belonging to a compact subset of $\mathrm{R}^{d}$. For instance, $M^{j, k, l}$ is characterized by its expectation $\mu^{j, k, l}$, with $\mu^{j, k, l} \in\left[\underline{\mu}^{j, k, l}, \bar{\mu}^{j, k, l}\right]$, where $\underline{\mu}^{j, k, l}$ denotes the lower bound on values of parameter $\mu^{j, k, l}$ and $\bar{\mu}^{j, k, l}$ denotes the upper bound.

The risk-neutral manager's expected utility is $V^{i, j, k}$, where $i$ denotes the level of company stock $c$ with $i=0, c$. The manager seeks to maximize the expected value of his/her wealth given the uncertainty and ambiguity regarding some parameters that we define in the following. The manager's initial wealth $W_{d}$ is positive and wholly invested in company stock. When the manager offers employee ownership, it takes the form of a contribution in company stock denoted by $c$. We assume $c$ to be a proportion of $W_{s}$, which is the positive initial employee's wealth. While the manager cannot directly observe the employees' wealth, (many employee characteristics that correlate with overall wealth can be observed such as age, gender, tenure, rank, level of education, fixed wage and bonus. Altogether, these variables make it possible to commensurate the employee ownership policy with the employees' wealth. $c W_{s}$ is therefore the monetary value of company stock granted to the employee that decreases the manager's initial wealth $W_{d}$. Indeed, the monetary value of the contribution granted to the employee is often commensurate with the amount invested by the employee. This may take the form of a discount or a matching contribution for instance. Degeorge et al (2004) provide empirical evidence that wealthier employees are more willing to invest in their company stocks. If the manager grants a contribution in company stock, the manager's expected wealth is given by equation (4); otherwise, the manager's expected wealth is given by equation (3). 


$$
\begin{aligned}
& V^{0, j, k}=\operatorname{Min}_{P_{R, M}^{j, k, m} \in \Delta_{m}}\left(W_{d} E\left[1+R+M^{j, k, m}\right]+C_{m}\left(P_{R, M^{j, k, m}}\right)\right) \\
& =\operatorname{Min}_{P_{R, M^{j, k, m}} \in \Delta_{m}}\left(W_{d}\left[1+\mu^{j, k, m}\right]+C_{m}\left(P_{R, M^{j, k, m}}\right)\right) \\
& V^{c, j, k}=\operatorname{Min}_{P_{R, M}, k, m_{\in \Delta_{m}}}\left(\left(W_{d}-c W_{s}\right) \mathrm{E}\left[\left(1+R+M^{j, k, m}\right)\right]+C_{m}\left(P_{R, M^{j, k, m}}\right)\right)
\end{aligned}
$$

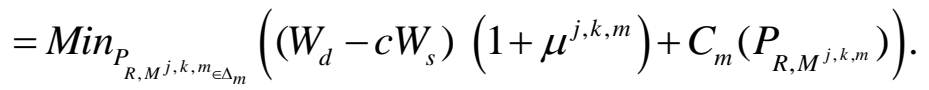

LEMMA 1 Since the set $\Delta_{m}$ of multipriors is compact, the utility $V^{0, j, k}$ corresponds to

$$
V^{0, j, k}=W_{d}\left[1+\mu^{0, j, k, m, *}\right]+C_{m}\left(P_{R, M^{0, j, k, m, *}}\right),
$$

for a given $P_{R, M^{0, j, k, m, *}}$ in $\Delta_{m}$, and $V^{c, j, k}$ corresponds to

$$
V^{c, j, k}=\left(W_{d}-c W_{s}\right)\left[1+\mu^{c, j, k, m, *}\right]+C_{m}\left(P_{R, M^{c, j, k, m, *}}\right),
$$

for another given $P_{R, M^{c, j, k, m, *}}$ in $\Delta_{m}$.

The risk-averse employee's expected utility is considered to be additively separable between the gains and the disutility of effort. The employee's positive initial wealth $W_{s}$ is wholly invested in a risk-free asset whose rate of return is $r_{0}$. Effort $e$ is costly to the employee who endures $\psi(e)$, the disutility that increases with effort. If company stock is granted, the initial employee's wealth $W_{s}$ increases by the amount $c W_{s}$. If the employee receives $c W_{s}$, his or her expected utility is given by equation (6), otherwise, it is given by equation (5):

$$
U^{0, j}=u\left[W_{s}\left(1+r_{0}\right)\right]-\psi\left(e^{j}\right)
$$

and:

$$
\begin{aligned}
& U^{c, j}=\operatorname{Min}_{P_{R, M}^{j}, k, e_{\epsilon} \in A_{e}} \\
& E\left(\begin{array}{c}
p_{0}\left(u\left[W_{s}\left(1+r_{0}\right)+c W_{s}\left(1+R+M^{j, G, e}\right)\right]+C_{e}\left(P_{R, M^{j, G, e}}\right)\right) \\
+\left(1-p_{0}\right)\left(u\left[W_{s}\left(1+r_{0}\right)+c W_{s}\left(1+R+M^{j, B, e}\right)+C_{e}\left(P_{R, M^{j, B, e}}\right)\right]\right)
\end{array}\right) \\
& -\psi\left(e^{j}\right) \text {. }
\end{aligned}
$$

where $u($.$) is a risk-averse von Neumann-Morgenstern utility function.$

LEMMA 2 Since the set $\Delta_{e}$ of multipriors is compact, the utility $U^{c, j}$ corresponds to

$$
\begin{aligned}
& E\left(\begin{array}{c}
p_{0}\left(u\left[W_{s}\left(1+r_{0}\right)+c W_{s}\left(1+R+M^{c, j, G, e^{*}}\right)+C_{e}\left(P_{R, \mu^{c, j, G, e, *}}\right)\right]\right) \\
+\left(1-p_{0}\right)\left(u\left[W_{s}\left(1+r_{0}\right)+c W_{s}\left(1+R+M^{c, j, B, e^{*}}\right)\right]+C_{e}\left(P_{R, \mu^{c, j, B, e, *}}\right)\right)
\end{array}\right) \\
& -\psi\left(e^{j}\right) .
\end{aligned}
$$


for the given $P_{R, M^{c, j, G, e, *}}$ and $P_{R, M^{c, j, B, e, *},}$ in $\Delta_{e}$.

EXAMPLE 1 A basic example corresponds to straightforward ambiguity about the parameter values of the joint distributions of $R$ and $M^{j, k, e}, M^{j, k, m}$. We assume that $R$ follows a centered Gaussian distribution $\mathbf{N}(0, \sigma)$ and $M^{j, k, m}$ and $M^{j, k, e}$ are respectively equal to constants $\mu^{j, k, m}$ and $\mu^{j, k, e}$ belonging to given subsets $\left[\underline{\mu}^{j, k, m}, \bar{\mu}^{j, k, m}\right]$ and $\left[\underline{\mu}^{j, k, e}, \bar{\mu}^{j, k, e}\right]$.

We make the following assumptions about the utility function of the employee and the parameters:

\section{ASSUMPTION 2}

1) The employee is risk-averse and cautious (Gollier, 2008).

$$
\forall x: u^{\prime}(x)>0, u^{\prime \prime}(x)<0, R R A(x)=-x \frac{u^{\prime \prime}(x)}{u^{\prime}(x)} \leq 1 .
$$

This assumption is equivalent to $\forall x,\left[x u^{\prime}(x)\right]^{\prime} \geq 0$, which implies that $x \rightarrow x u^{\prime}(x)$ is an increasing function.

2) The employee's expected utility is strictly positive when company stock is not granted and effort is low:

$$
U^{0, L}=u\left[W_{s}\left(1+r_{0}\right)\right]-\psi\left(e^{L}\right)>0 .
$$

This assumption implies in particular that the disutility for low effort is relatively small (upper bounded by $\left.u\left[W_{s}\left(1+r_{0}\right)\right]\right)$.

3) The employee's expected utility is higher with employee ownership for a given level of effort:

$$
U^{c, j} \geq U^{0, j}, \forall c>0, \forall j=\{H, L\} .
$$

This assumption means that, whatever the level of effort, the employee benefits from receiving a non-zero contribution.

\subsection{Derivation of the optimal contract}

In what follows, we derive the model solutions and detail the conditions under which employee ownership is used either as an entrenchment tool or as a reward mechanism. We describe the employee ownership contract with ambiguity aversion when there is no threat of dismissal for the manager. We define $\omega(c)$ as the difference between the employee's utility of wealth when a high level of effort is exerted and the utility of wealth resulting from a low level of effort (without taking into account the respective disutilities resulting from the effort). The difference is given by:

$$
\omega(c)=
$$




$$
\begin{gathered}
E\left(\begin{array}{c}
p_{0}\left(u\left[W_{s}\left(1+r_{0}\right)+c W_{s}\left(1+R+M^{c, H, G, e^{*}}\right)+C_{e}\left(P_{R, M^{c, H, G, e, *}}\right)\right]\right) \\
+\left(1-p_{0}\right)\left(u\left[W_{s}\left(1+r_{0}\right)+c W_{s}\left(1+R+M^{c, H, B, e^{*}}\right)\right]+C_{e}\left(P_{R, M^{c, H, B, e, *}}\right)\right)
\end{array}\right) \\
-E\left(\begin{array}{c}
p_{0}\left(u \left[W_{s}\left(1+r_{0}\right)+c W_{s}\left(1+R+M^{c, L, G, e^{*}}\right)+C_{e}\left(P_{\left.\left.R, M^{c, L, G, e, *}\right)\right]}\right)\right.\right. \\
+\left(1-p_{0}\right)\left(u\left[W_{s}\left(1+r_{0}\right)+c W_{s}\left(1+R+M^{c, L, B, e^{*}}\right)\right]+C_{e}\left(P_{R, M^{c, L, B, e, *}}\right)\right)
\end{array}\right)
\end{gathered}
$$

The employee chooses the high level of effort if this difference is greater than the supplementary disutility of effort $\psi\left(e^{H}\right)-\psi\left(e^{L}\right)$ needed to reach this level of effort.

First, we consider a case which is a straightforward extension of the framework introduced by Aubert et al (2014). We get the following result:

PROPOSITION 1 Assume we are dealing with the basic example 1. Recall in particular that both ambiguity indices $C_{m}$ and $C_{e}$ are null (as in the framework of Gilboa and Schmeidler, 1989) and that ambiguity exists only for $\mu^{j, k, m} \in\left[\underline{\mu}^{j, k, m}, \bar{\mu}^{j, k, m}\right]$ and $\mu^{j, k, e} \in\left[\underline{\mu}^{j, k, e}, \bar{\mu}^{j, k, e}\right]$ with $\underline{\mu}^{j, k, m}=\underline{\mu}^{j, k, e}$. Thus, we recover the model introduced by Aubert et al (2014) exactly, with $\bar{\mu}=\underline{\mu}^{L, B, m}=\underline{\mu}^{L, B, e} ; \mu+\alpha=\underline{\mu}^{L, G, m}=\underline{\mu}^{L, G, e} ; \mu+\beta=\underline{\mu}^{H, B, m}=\underline{\mu}^{H, B, e} ; \mu+\alpha+\beta=\underline{\mu}^{j, H, G}=\underline{\mu}^{j, H, G}$.

Proof: The result is proved by using the fact that both utilities are increasing functions of all the parameters $\mu^{j, k}$.

Second, we investigate a more general framework. For this purpose, we introduce some specific conditions which allow us to establish the mild properties of $\omega(c)$, leading to the derivation of the optimal solutions (see Assumption 3).

NOTATION 1 Denotes the four kinds of wealth level for the employee:

$$
\begin{aligned}
& X=W_{s}\left(1+r_{0}\right)+c W_{s}\left(1+r+M^{c, H, G, e, *}\right) \\
& Y=W_{s}\left(1+r_{0}\right)+c W_{s}\left(1+r+M^{c, L, G, e, *}\right) \\
& Z=W_{s}\left(1+r_{0}\right)+c W_{s}\left(1+r+M^{c, H, B, e, *}\right) \\
& T=W_{s}\left(1+r_{0}\right)+c W_{s}\left(1+r+M^{c, L, B, e, *}\right)
\end{aligned}
$$

\section{ASSUMPTION 3}

1) We assume that, despite ambiguity, the employee is more optimistic about the value of his or her wealth when making an effort, whatever the quality of the manager. This means that we have $X>Y$ and $Z>T$. Thus, using assumption (2), we get the following inequalities: for any value $r$ of $R$, 


$$
\begin{aligned}
& E_{M^{c, L, G, G, *}}\left[u^{\prime}(Y)\right]>E_{M^{c, H, G, G, *}}\left[u^{\prime}(X)\right], \\
& E_{M^{c, L, B, B, e *}}\left[u^{\prime}(T)\right]>E_{M^{c, H, B, e_{e}, *}}\left[u^{\prime}(Z)\right], \\
& E_{M^{c, H, G, e *}}\left[X u^{\prime}(X)\right] \geq E_{M^{c, L, G, Q_{*} *}}\left[Y u^{\prime}(Y)\right], \\
& E_{M^{c, H, B, e, *}}\left[Z u^{\prime}(Z)\right] \geq E_{M^{c, L, B, e, *}}\left[T u^{\prime}(T)\right] .
\end{aligned}
$$

2) The sensitivities of the optimal probability distributions $M^{c, j, k, e *}$ to the level of company stock $c$ weighted by the employee's marginal utility are higher when the employee makes an effort, whatever the quality of the manager:

$$
\begin{aligned}
& E_{M^{c, H, G, e, *}}\left[\left(\partial M^{c, H, G, e^{*}} / \partial c\right) u^{\prime}(X)\right] \geq E_{M^{c, L, G, e * *}}\left[\left(\partial M^{c, L, G, e^{*}} / \partial c\right) u^{\prime}(Y)\right], \\
& E_{M^{c, H, B, B, *}}\left[\left(\partial M^{c, H, B, e *} / \partial c\right) u^{\prime}(Z)\right] \geq E_{M^{c, L, B, e^{*}}}\left[\left(\partial M^{c, L, B, e^{*}} / \partial c\right) u^{\prime}(T)\right] .
\end{aligned}
$$

3) When the employee makes an effort, the latter's ambiguity index is more sensitive to the level of employee ownership:

$$
\frac{\partial\left[C_{e}\left(P_{R, M^{c, H, G, e *}}\right)-C_{e}\left(P_{R, M^{c, L, G, e *}}\right)\right]}{\partial c} \geq 0, \frac{\partial\left[C_{e}\left(P_{R, M^{c, H, B, e+e}}\right)-C_{e}\left(P_{R, M^{c, L, B, e+e}}\right)\right]}{\partial c} \geq 0 .
$$

PROPOSITION 2 Under assumption (3), the difference between the employee's utilities of wealth with high and low levels of effort defined by $\omega(c)$ has the following properties: $\omega(0)=0$ and $\omega^{\prime}(c)>0$.

Proof: See Appendix.

The previous result means that the greater the contribution of the employee in the company stock, the higher the difference between the satisfaction level when the employee makes an effort and the higher the satisfaction level when the employee does not make this effort. Recall that $\omega(c)$ does not take the effort's disutility into account.

COROLLARY 1 For the basic example 1, with a null ambiguity index $C_{e}$ such that $\mu^{H, G, e} \geq \mu^{L, G, e}$ and $\mu^{H, B, e} \geq \mu^{L, B, e}$, we deduce the two properties $\omega(0)=0$ and $\omega^{\prime}(c)>0$, from Assumption (2).

Proof: See Appendix.

Taking ambiguity into account, the equilibrium is obtained if the manager grants a positive amount of company stock and if the employee exerts a high level of effort. Although other solutions may be investigated, we focus on the situation where the employee exerts a high level of effort in the presence of a positive level of employee ownership. We thus illustrate the manager's strategies by examining a scenario that is the most widely identified by the literature on employee ownership.

This situation describes a perfect subgame Nash equilibrium where managers' and employees' utilities are, respectively, $V^{c^{*}, H, k}$ and $U^{c^{*}, H, k}$, and where $c^{*}$ is the equilibrium contribution in company stock. The value $\mathcal{c}_{k}^{*}$ is given by the manager's participation condition $V^{c, H, k} \geq V^{0, L, k}$. 
$\mathcal{C}_{k}$ represents the maximum compensation that can be granted by the manager. Above $\mathcal{c}_{k}$, employee ownership becomes too costly for the manager.

The two threshold constraints $\overline{c_{G}}$ and $\overline{c_{B}}$ differ according to the two types of managers who know their type, but which cannot be observed by the employee. Indeed, $\overline{c_{G}} \leq \overline{c_{B}}$.

Consider the following equation corresponding to the equality of $V^{c, H, k}$ and $V^{0, L, k}$ with unknown variable $c$ :

$$
\begin{aligned}
& \left(\left(W_{d}-c W_{s}\right)\left[\left(1+\mu^{c, H, k, m, *}\right)\right]+C_{m}\left(P_{R, M^{c, H, H, m, *}}\right)\right) \\
= & \left(W_{d}\left[1+\mu^{0, L, k, m, *}\right]+C_{m}\left(P_{\left.R, M^{0, L, k, m, *}, *\right) .}\right.\right.
\end{aligned}
$$

The manager's expected wealth $V^{c, H, k}$ must decrease with respect to the contribution $c$ in company stock.

We thus state the following proposition.

PROPOSITION 3 If $V^{c, H, k}$ is strictly decreasing with respect to the contribution $c$, then threshold $\mathcal{c}_{k}^{*}$ is the unique solution of Equation (12).

The previous result is illustrated by the two following fundamental examples.

EXAMPLE 2 If the ambiguity index is null (i.e. $C_{m}=0$ ), then:

$$
\mathscr{C}_{k}=\frac{W_{d}}{W_{s}} \frac{\underline{\mu}^{H, k, m, *}-\underline{\mu}^{L, k, m, *}}{1+\underline{\mu}^{H, k, m, *}} .
$$

In this case, using assumptions of the basic example 1 , the threshold $\mathcal{C}_{k}$ increases with respect to $\underline{\mu}^{H, k, m, *}$, meaning that the higher the minimum return expectation when the employee makes an effort, the higher the contribution given to the employee. On the contrary, the threshold $\mathcal{C}_{k}$ decreases with respect to $\underline{\mu}^{L, k, m, *}$, meaning that the higher the minimum return expectation when the employee does not make an effort, the smaller the contribution given to the employee. If $\mu^{L, k, m, *}$ is high, the manager does not need to significantly remunerate the employee. Note that, if we compare the above solution to the solution when there is no ambiguity corresponding to a unique value $\mu^{H, k, m}$, the contribution granted to the employee is smaller when the manager faces ambiguity since obviously $\underline{\mu}^{H, k, m, *} \leq \mu^{H, k, m}$.

EXAMPLE 3 If the ambiguity index corresponds to the Log entropy, then if the aversion to ambiguity is sufficiently high, i.e. $\xi \geq \frac{\sigma^{2} W_{d}}{\left(1+\mu_{0}^{H, k, m}\right)}$, the function $\omega(c)$ is decreasing, which corresponds exactly to the assumption of Proposition 3. This means that if the aversion to ambiguity is sufficiently high, then we find the same behavior as in the no ambiguity case.

Note that the ambiguity index of the manager $C_{m}\left(P_{\left.R, M^{c, H, H, m_{*}^{*}}\right)}\right)$ is itself decreasing, which means that the higher the contribution $c$ given by the manager to the employee, the higher the manager's aversion to ambiguity.

Proof: See Appendix. 


\section{PROPOSITION 4}

Under previous assumptions, for $\omega^{-1}\left[\psi\left(e^{H}\right)-\psi\left(e^{L}\right)\right] \leq \overline{c_{G}}$, there is a unique $c^{e}=c^{*} \in\left(0, \overline{c_{G}}\right]$ which is the perfect subgame Nash equilibrium. With $c^{e}$, the employee expends a high level of effort ( $j=H$ ) regardless of the manager's type. Level $c^{*}$ is given by the following relationship:

$$
\omega\left(c^{*}\right)=\psi\left(e^{H}\right)-\psi\left(e^{L}\right) .
$$

Proof: See Appendix.

We illustrate the previous result by the following example.

EXAMPLE 4 Suppose that both ambiguity indices $C_{m}$ and $C_{e}$ are null. Let's assume that the probability distribution of $(1+R)$ is Lognormal $L N\left(-\sigma^{2} / 2, \sigma\right)$ and that $M^{j, k, e}$ is equal to $\mu^{j, k, e}$ with $\mu^{j, k, e} \in\left[\underline{\mu}^{j, k, e}, \bar{\mu}^{j, k, e}\right]$. Consider the utility function given by $u(v)=v^{(1-\gamma)} /(1-\gamma)$ with $0<\gamma<1$. Note that this utility function satisfies Assumption 2. We now determine the employee's expected utility $U^{c, j}$. Remember that $U^{c, j}$ is defined by:

$$
\begin{aligned}
U^{c, j}= & \operatorname{Min}_{P_{R, M} j, k, e_{\in \Delta_{e}}} \\
& E\left(\begin{array}{c}
p_{0} u\left[W_{s}\left(1+r_{0}\right)+c W_{s}\left(1+R+M^{j, G, e}\right)\right] \\
+\left(1-p_{0}\right) u\left[W_{s}\left(1+r_{0}\right)+c W_{s}\left(1+R+M^{j, B, e}\right)\right]
\end{array}\right) \\
& -\psi\left(e^{j}\right) .
\end{aligned}
$$

Given the above assumptions, we have $1+R+M^{j, G, e}=e^{-\sigma^{2} / 2+\sigma N}+\mu^{j, G, e}$ and $1+R+M^{j, B, e}=e^{-\sigma^{2} / 2+\sigma N}+\mu^{j, B, e}$, where $N$ denotes a Gaussian random variable with zero mean and standard deviation equal to 1 . Thus, we have:

$$
\begin{aligned}
& E\left[u\left[W_{s}\left(1+r_{0}\right)+c W_{s}\left(1+R+M^{j, G, e}\right)\right]\right]=\left(W_{s}\left(1+r_{0}\right)+c W_{s}\left[e^{-\sigma^{2} / 2+\sigma N}+\mu^{j, G, e}\right]\right)^{(1-\gamma)} /(1-\gamma) \\
& E\left[u\left[W_{s}\left(1+r_{0}\right)+c W_{s}\left(1+R+M^{j, B, e}\right)\right]\right]=\left(W_{s}\left(1+r_{0}\right)+c W_{s}\left[e^{-\sigma^{2} / 2+\sigma N}+\mu^{j, B, e}\right]\right)^{(1-\gamma)} /(1-\gamma)
\end{aligned}
$$

The two previous terms increase respectively with respect to $\mu^{j, G, e}$ and $\mu^{j, B, e}$.

We now examine $\omega(c)=U^{c, H}-U^{c, L}$ which corresponds to $\mu^{H, G, e, *}=\underline{\mu}^{H, G, e}, \mu^{H, B, e, *}=\underline{\mu}^{H, B, e}$ and $\mu^{L, G, e, *}=\bar{\mu}^{L, G, e}, \mu^{L, B, e, *}=\bar{\mu}^{L, B, e}$. Thus, we get:

$$
\omega(c)=\frac{1}{(1-\gamma)} \times
$$




$$
\begin{gathered}
p_{0}\left(\begin{array}{l}
\left(W_{s}\left(1+r_{0}\right)+c W_{s}\left[e^{-\sigma^{2} / 2+\sigma N}+\underline{\mu}^{H, G, e}\right]\right)^{(1-\gamma)} \\
-\left(W_{s}\left(1+r_{0}\right)+c W_{s}\left[e^{-\sigma^{2} / 2+\sigma N}+\bar{\mu}^{L, G, e}\right]\right)^{(1-\gamma)}
\end{array}\right) \\
+\left(1-p_{0}\right)\left(\begin{array}{l}
\left(W_{s}\left(1+r_{0}\right)+c W_{s}\left[e^{-\sigma^{2} / 2+\sigma N}+\underline{\mu}^{H, B, e}\right]\right)^{(1-\gamma)} \\
-\left(W_{s}\left(1+r_{0}\right)+c W_{s}\left[e^{-\sigma^{2} / 2+\sigma N}+\bar{\mu}^{L, B, e}\right]\right)^{(1-\gamma)}
\end{array}\right)
\end{gathered}
$$

Assumption 3 is satisfied since all three of its assertions are verified (in particular, $\mu^{H, G, e, *}$, $\mu^{H, B, e, *}, \mu^{L, G, e, *}$ and $\mu^{L, B, e, *}$ do not depend on c, implying that assertion (2) is satisfied). Therefore, from Proposition 2, we deduce that $\omega(c)$ is decreasing with respect to $c$. We also note that $\omega(c)$ is respectively increasing with respect to $\mu^{H, G, e}$ and $\mu^{H, B, e}$ (corresponding to a high level of effort) and decreasing with respect to $\bar{\mu}^{L, G, e}$ and $\bar{\mu}^{L, B, e}$ (corresponding to a low level of effort). Finally, using the theorem of implicit functions, the optimal ownership contract $c^{*}$ is respectively increasing with respect to $\underline{\mu}^{H, G, e}$ and $\underline{\mu}^{H, B, e}$, and decreasing with respect to $\bar{\mu}^{L, G, e}$ and $\bar{\mu}^{L, B, e}$. This property related to the employee's ambiguity is analogous to the sensitivities of the threshold $\mathcal{C}_{k}$ corresponding to the manager.

EXAMPLE 5 Consider the assumptions of example 5 and suppose that the utility function is given by $u(v)=-e^{-a v} / a$ with $a>0$. We define the employee's expected utility $U^{c, j} . U^{c, j}$ by:

$$
\begin{aligned}
& U^{c, j}=\operatorname{Min}_{P_{R, M} j, k, e \in \triangle_{e}} \\
& E\left(\begin{array}{c}
p_{0} u\left[W_{s}\left(1+r_{0}\right)+c W_{s}\left(1+R+M^{j, G, e}\right)\right] \\
+\left(1-p_{0}\right) u\left[W_{s}\left(1+r_{0}\right)+c W_{s}\left(1+R+M^{j, B, e}\right)\right]
\end{array}\right) \\
& -\psi\left(e^{j}\right) .
\end{aligned}
$$

Due to the above assumptions, we have $1+R+M^{j, G, e}=1+\sigma N+\mu^{j, G, e} \quad$ and $1+R+M^{j, B, e}=1+\sigma N+\mu^{j, B, e}$, where $N$ denotes a Gaussian random variable with zero mean and standard deviation equal to 1 . Thus, we have:

$$
\begin{aligned}
& E\left[u\left[W_{s}\left(1+r_{0}\right)+c W_{s}\left(1+R+M^{j, G, e}\right)\right]\right]=-\exp \left[-a\left(W_{s}\left(1+r_{0}\right)+c W_{s}\left[1+\mu^{j, G, e}\right]\right)+\frac{\left(a \sigma c W_{s}\right)^{2}}{2}\right] / a \\
& E\left[u\left[W_{s}\left(1+r_{0}\right)+c W_{s}\left(1+R+M^{j, B, e}\right)\right]\right]=-\exp \left[-a\left(W_{s}\left(1+r_{0}\right)+c W_{s}\left[1+\mu^{j, B, e}\right]\right)+\frac{\left(a \sigma c W_{s}\right)^{2}}{2}\right] / a
\end{aligned}
$$

The two previous terms increase respectively with respect to $\mu^{j, G, e}$ and $\mu^{j, B, e}$.

We now examine $\omega(c)=U^{c, H}-U^{c, L}$. This corresponds to $\mu^{H, G, e, *}=\underline{\mu}^{H, G, e}, \mu^{H, B, e, *}=\underline{\mu}^{H, B, e}$ and 
$\mu^{L, G, e, *}=\bar{\mu}^{L, G, e}, \mu^{L, B, e, *}=\bar{\mu}^{L, B, e}$. Therefore, we get:

$$
\begin{aligned}
& \omega(c)=-\frac{1}{a} \times \\
& p_{0}\left(\begin{array}{c}
\exp \left[-a\left(W_{s}\left(1+r_{0}\right)+c W_{s}\left[1+\underline{\mu}^{H, G, e}\right]\right)+\frac{\left(a \sigma c W_{s}\right)^{2}}{2}\right] \\
-\exp \left[-a\left(W_{s}\left(1+r_{0}\right)+c W_{s}\left[1+\bar{\mu}^{L, G, e}\right]\right)+\frac{\left(a \sigma c W_{s}\right)^{2}}{2}\right]
\end{array}\right) \\
& +\left(1-p_{0}\right)\left(\begin{array}{c}
\exp \left[-a\left(W_{s}\left(1+r_{0}\right)+c W_{s}\left[1+\underline{\mu}^{H, B, e}\right]\right)+\frac{\left(a \sigma c W_{s}\right)^{2}}{2}\right] \\
-\exp \left[-a\left(W_{s}\left(1+r_{0}\right)+c W_{s}\left[1+\bar{\mu}^{L, B, e}\right]\right)+\frac{\left(a \sigma c W_{s}\right)^{2}}{2}\right]
\end{array}\right)
\end{aligned}
$$

Note that Assumption 2 is no longer satisfied since $R R A(x)=a x$ is not upper bounded for $x \in\left[0,+\infty\left[\right.\right.$. However, first $\omega(c)$ is still respectively increasing with respect to $\underline{\mu}^{H, G, e}$ and $\underline{\mu}^{H, B, e}$ (corresponding to a high level of effort) and decreasing with respect to $\overline{\bar{\mu}}_{\mu, G, e}$ and $\overline{-}^{L, B, e}$ (corresponding to a low level of effort). Let's additionally assume that $\underline{\mu}^{H, G, e}>\bar{\mu}^{L, G, e}$ and $\underline{\mu}^{H, B, e}>\bar{\mu}^{L, B, e}$. Thus, we have $c_{\min }$, such that for $c \geq c_{\min }, \omega(c)$ is decreasing with respect to $c$. In such a case, we recover the property given in Proposition 2. Therefore, the optimal ownership contract $c^{*}$ is respectively increasing with respect to $\underline{\mu}^{H, G, e}$ and $\underline{\mu}^{H, B, e}$, and decreasing with respect to $\bar{\mu}^{L, G, e}$ and $\bar{\mu}^{L, B, e}$.

\section{Concluding remarks}

In this paper, we introduce ambiguity aversion to a model setup previously advanced by Aubert et al (2014). In this model, the authors consider that managerial monetary contributions in company stocks to the employee reveal the management type. The present paper proposes a sequential game where a risk-neutral manager grants company stocks to an ambiguity-averse employee. We focus on the most common situation in which employee ownership positively affects corporate performance. While previous experimental and empirical literature has documented behavioral cognitive biases affecting employees when their employer's stocks are offered, this paper is the first attempt to take ambiguity into account in a theoretical model. We extend the results of Aubert et al (2014) in the framework of ambiguity using the multiple prior preferences of Gilboa and Schmeidler's (1989) and its extension provided by Maccheroni et al (2006). We provide a general outcome of optimal employee ownership under ambiguity. The optimal contribution in company stock is determined in the situation described by a subgame perfect Nash equilibrium.

We show that in the framework of Gilboa and Schmeidler (1989), first, the higher the minimum return expectation when the employee makes an effort, the higher the contribution given to the employee. Second, the higher the minimum return expectation when the employee does not make an effort, the smaller the contribution given to the employee. Third, if the lower bound of the 
mean of the company excess returns in the case of low effort is high, the manager does not need to significantly remunerate the employee.

Concerning the optimal ownership contract, we show that the contribution in company stocks respectively increases with respect to the lower bound of the return expectation in the case of a high level of effort and decreases with respect to the upper bound of the return expectation in the case of a low level of effort. In the framework of Maccheroni et al (2006), we prove first that, if the aversion to ambiguity is sufficiently high, then we find the same behavior as in the no ambiguity case. Second, the contribution given to the employee by the manager decreases when the manager faces stronger ambiguity.

\section{References}

Aubert, N., Garnotel, G., Lapied, A., and Rousseau, P., Employee ownership: a theoretical and empirical investigation on reward management vs. management entrenchment. Economic Modelling, 40, 2014, 423-434.

Barber, B. and Odean T., The behavior of individual investors, in Handbook of the economics of finance. G. Constantinides and R. Stulz eds, Elsevier Publishing, 2013.

Beatty, A. The cash flow and informational effects of ESOP. Journal of Financial Economics, 38,1995, 211-240.

Benartzi, S., Excessive extrapolation and the allocation of company stock to retirement accounts. Journal of Finance, 56, 2001, 1747-1764.

Benartzi, S., Thaler, R., Utkus S., Sunstein C., The law and economics of company stock in 401(k) plans. Journal of Law and Economics, 50, 2007, 45-79.

Benartzi, Shlomo, and Richard H. Thaler, Risk aversion or myopia? Choices in repeated gambles and retirement investments, Management Science, 45, 1999, 364-381.

Benartzi, Shlomo and Richard H. Thaler, How much is investor autonomy worth?, Journal of Finance, 57, 2002, 1593-1616.

Blasi, J. R., Freeman, R. B. and Kruse, D. L. The citizen's share: Putting ownership back into democracy. Yale University Press, 2013.

Brown J., Liang N. and Weisbenner S., 401(k) matching contributions in company stock: costs and benefits for firms and workers. Journal of Public Economics, 90, 2006, 1315-1346.

Campbell, J., Household finance, Journal of Finance, 51, 2006, 1553-1599.

Chang, S. ESOPs and shareholder wealth: an empirical investigation. Financial Management, 19, 1990, 48-58.

Chang, S. and Mayers, D., Managerial vote ownership and shareholder wealth: evidence from ESOP. Journal of Financial Economics, 32, 1992, 103-131.

Chaplinsky, S. and Niehaus, G., The role of ESOPs in takeover contests. Journal of Finance 49, 1994, 1451-1470.

Charness, G. and Gneezy U., Portfolio choice and risk attitudes: an experiment, Economic Inquiry, 48,2010, 133-146.

Choi, J., D. Laibson, B. Madrian, and A. Metrick, Employees' investment decisions about company stock, in Olivia S. Mitchell and Stephen P. Utkus, eds.: Pension Design and 
Structure: New Lessons from Behavioral Finance (Oxford University Press, New York, NY). 2004.

Cohen, L., Loyalty-based portfolio choice. Review of Financial Studies, 22, 2009, 1213-1245.

Conte, M., Blasi, J., Kruse, D. and Jampani, R., Financial returns of public ESOP companies: investors effects vs. manager effects. Financial Analyst Journal, 52, 1996, 51-61.

Degeorge, F., Jenter, D., Moel, A. and Tufano, P., Selling company shares to reluctant employees: France Telecom's experience. Journal of Financial Economics, 71, 2004, 169202.

Ellsberg, D., Risk, ambiguity, and the Savage axioms. Quarterly Journal of Economics, 75, 1961, 643-669.

Gilboa, I., and Schmeidler, D,. Maxmin expected utility with a non-unique prior. Journal of Mathematical Economics, 18, 1989,141-153.

Gollier, C., Understanding saving and portfolio choices with predictable changes in assets returns. Journal of Mathematical Economics, 44, 2008. 445-458.

Guiso, L. and Sodini, P., Household finance: an emerging field, in Handbook of the economics of finance, in G. Constantinides, M. Harris and R. Stulz eds, 2013, 1397-1532.

Hansen, L. and Sargent, T. Wanting robustness in macroeconomics. In Handbook of Monetary Economics, B. M. Friedman and M. Woodford ed., North-Holland, 2000

Hansen, L. and Sargent, T. 2001. Robust control and model uncertainty. American Economic Review, 91, 60-66.

Holden, S. and Van Derhei, J., 401(k) plan asset allocation, account balances, and loan activity in 2000. ICI Perspectives. 7, 2001, 1-27.

Huberman, G., Familiarity breeds investment, Review of Financial Studies, 14, 2001 659-680.

Kaarsemaker E., Employee ownership and its consequences: Synthesis-generated evidence for the effects of employee ownership and gaps in the research literature. University of York, 2006.

Kruse, D., Freeman, R. B. and Blasi, J. (Eds.). Shared capitalism at work: Employee ownership, profit and gain sharing, and broad-based stock options. In Shared Capitalism at Work: Employee Ownership, Profit and Gain Sharing, and Broad-based Stock Options, Editors: Douglas L. Kruse, Richard B. Freeman and Joseph R. Blasi, University of Chicago Press, 2010.

Kruse, D., Research evidence on prevalence and effects of employee ownership. Paper presented in testimony before the subcommittee on employee-employer relations, Committee on Education and Workforce, U. S. House of Representatives, Feb. 13. 2002.

Maccheroni, F., Marinacci, M. and Rustichini, A., Ambiguity aversion, robustness, and the variational representation of preferences. Econometrica, 74(6), 2006, 1447-1498.

Madrian, Brigitte C., \& Dennis F. Shea, The power of suggestion: Inertia in 401(k) participation and savings behavior, Quarterly Journal of Economics, 116, 2001, 1149-1525.

Mitchell, O. and S. Utkus. 2003. Company Stock and Retirement Plan Diversification. In The Pension Challenge: Risk Transfers and Retirement Income Security, eds. Olivia S. Mitchell and Kent Smetters. Oxford: Oxford University Press, 2003, 33-70.

O'Boyle, E. H., Patel, P. C. and Gonzalez-Mulé, E., Employee ownership and firm performance: a meta-analysis. Human Resource Management Journal, 26(4), 2016, 425-448.

Pagano, M. and Volpin, P., Workers, managers, and corporate control. Journal of Finance 60, 2005, 841-868.

Park, S. and Song M., Employee stock ownership plans, firm performance and monitoring by outside blockholders. Financial Management. 24, 1995, 52-65. 
Purcell, P., Pension Issues: Cash Balance Plans. CRS Report for Congress RL30196.

Rauh, J., Own company stock in defined contribution pension plans: a takeover defense? Journal of Financial Economics, 81, 2006, 379-410.

Shleifer, A. and Vishny, R. W., Management entrenchment: The case of manager-specific investments. Journal of Financial Economics, 25(1), 1989, 123-139.

Weitzman, M., The Share Economy: Conquering Stagflation. Cambridge: Harvard University Press, 1984.

\section{Appendix}

\section{PROOF OF PROPOSITION 2}

First we have $\omega(0)=0$. Indeed, when the contribution to the employee in the company stock is null, the expected utility of the employee, without taking their effort into account, always equals $U^{0, j}=u\left[W_{s}\left(1+r_{0}\right)\right]$. Thus, the difference $\omega(0)$ is null.

Let $\omega(c)$ be defined by Equation (11). Recall that we have:

$$
\begin{aligned}
& X=W_{s}\left(1+r_{0}\right)+c W_{s}\left(1+r+M^{c, H, G, e, *}\right) \\
& Y=W_{s}\left(1+r_{0}\right)+c W_{s}\left(1+r+M^{c, L, G, e, *}\right) \\
& Z=W_{s}\left(1+r_{0}\right)+c W_{s}\left(1+r+M^{H, B, e, *}\right) \\
& T=W_{s}\left(1+r_{0}\right)+c W_{s}\left(1+r+M^{L, B, e, *}\right)
\end{aligned}
$$

Therefore, we deduce:

$$
\begin{gathered}
\omega(c)= \\
\int_{-\infty}^{+\infty}\left(p_{0} E_{M^{c, H, G, e, *}}[u(X)]+\left(1-p_{0}\right) E_{M^{c, H, B, e, *}}[u(Z)]\right) f(r) d r \\
-\int_{-\infty}^{+\infty}\left(p_{0} E_{M^{c, L, G, e, *}}[u(Y)]+\left(1-p_{0}\right) E_{M^{c, L, B, e, * *}}[u(T)]\right) f(r) d r \\
+p_{0}\left[C_{e}\left(P_{R, M^{c, H, G, e *}}\right)-C_{e}\left(P_{R, M^{c, L, G, e *}}\right)\right]+\left(1-p_{0}\right)\left[C_{e}\left(P_{R, M^{c, H, B, e *}}\right)-C_{e}\left(P_{R, M^{c, L, B, e *}}\right)\right]
\end{gathered}
$$

For the second property, we note that:

$$
\omega^{\prime}(c)=
$$




$$
\begin{aligned}
& \frac{1}{c} \int_{-\infty}^{+\infty}\left(p_{0} E_{M^{c}, H, G, G, e, t}\left[X u^{\prime}(X)\right]+\left(1-p_{0}\right) E_{M^{c}, H, B, e, *}\left[Z u^{\prime}(Z)\right] f(r) d r\right. \\
& \left.-\frac{1}{c} \int_{-\infty}^{+\infty} p_{0} E_{\mu^{c, L, L, G, e,}}\left[Y u^{\prime}(Y)\right]+\left(1-p_{0}\right) E_{M^{c}, L, B,, e, t}\left[T u^{\prime}(T)\right]\right) f(r) d r \\
& -\frac{W_{s}\left(1+r_{0}\right)}{c} \int_{-\infty}^{+\infty}\left(p_{0} E_{M^{c, H, G, e, *}}\left[u^{\prime}(X)\right]+\left(1-p_{0}\right) E_{M^{c, H, B, e, *^{*}}}\left[u^{\prime}(Z)\right] f(r) d r\right. \\
& \left.+\frac{W_{s}\left(1+r_{0}\right)}{c} \int_{-\infty}^{+\infty} p_{0} E_{M^{c, L, L, G, e^{*}}}\left[u^{\prime}(Y)\right]+\left(1-p_{0}\right) E_{M^{c, L, B, B, e^{*}}}\left[u^{\prime}(T)\right]\right) f(r) d r \\
& +p_{0} \int_{-\infty}^{+\infty}\left(E_{M^{c, H, G, e, *}}\left[\left(\partial M^{c, H, G, e^{*}} / \partial c\right) u^{\prime}(X)\right]-E_{M^{c, L, G, e, *}}\left[\left(\partial M^{c, L, G, e *} / \partial c\right) u^{\prime}(Y)\right]\right) f(r) d r \\
& +\left(1-p_{0}\right) \int_{-\infty}^{+\infty}\left(E_{M^{c, H, B, B e *}}\left[\left(\partial M^{c, H, B, e^{*}} / \partial c\right) u^{\prime}(Z)\right]-E_{M^{c, L, B, e^{*}}}\left[\left(\partial M^{c, L, B, e^{*}} / \partial c\right) u^{\prime}(T)\right]\right) f(r) d r
\end{aligned}
$$

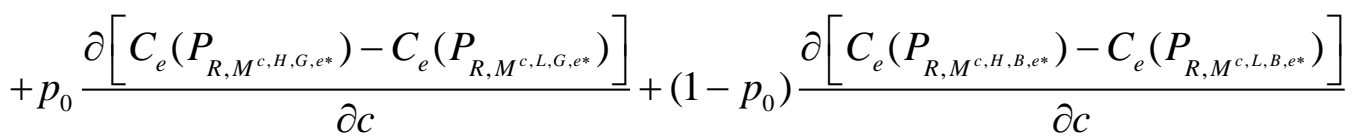

Using assertion (1) of Assumption 3, we have:

$$
\begin{aligned}
& E_{M^{c, L, G, e_{e, *}}}\left[u^{\prime}(Y)\right]>E_{M^{c, H, G, G, . *}}\left[u^{\prime}(X)\right], \\
& E_{M^{c, L, B, B, e, t}}\left[u^{\prime}(T)\right]>E_{M^{c, H, H, B, e,}}\left[u^{\prime}(Z)\right], \\
& E_{M^{c, H, G, e, *}}\left[X u^{\prime}(X)\right] \geq E_{M^{c, L, G, e, *}}\left[Y u^{\prime}(Y)\right], \\
& E_{M^{c, H, B, e, *}}\left[Z u^{\prime}(Z)\right] \geq E_{M^{c, L, B, \beta, *}}\left[T u^{\prime}(T)\right] .
\end{aligned}
$$

Using assertion (2) of Assumption 3, we have:

$$
\begin{aligned}
& E_{M^{c, H, G, e, *}}\left[\left(\partial M^{c, H, G, e^{*}} / \partial c\right) u^{\prime}(X)\right] \geq E_{M^{c, L, G, e, * *}}\left[\left(\partial M^{c, L, G, e^{*}} / \partial c\right) u^{\prime}(Y)\right], \\
& E_{M^{c, H, B, e^{*} *}}\left[\left(\partial M^{c, H, B, e *} / \partial c\right) u^{\prime}(Z)\right] \geq E_{M^{c, L, B, e^{*} *}}\left[\left(\partial M^{c, L, B, e^{*}} / \partial c\right) u^{\prime}(T)\right] .
\end{aligned}
$$

Using assertion (3) of Assumption (3), we have:

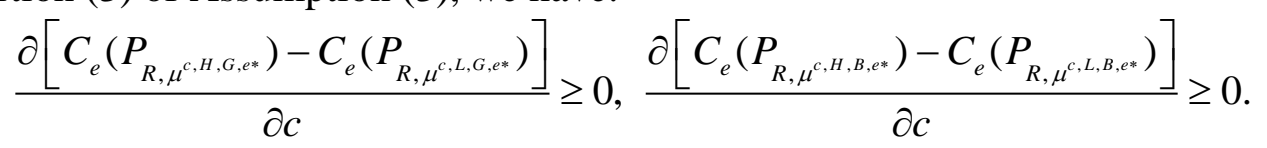

Therefore, we deduce the result.

\section{PROOF OF COROLLARY 1}

For the basic example, we get the result directly. Indeed, we have:

$$
\omega(c)=
$$




$$
\begin{aligned}
& \int_{-\infty}^{+\infty}\left(p_{0} u\left[W_{s}\left(1+r_{0}\right)+c W_{s}\left(1+r+\underline{\mu}^{H, G, e}\right)\right]\right. \\
& \left.+\left(1-p_{0}\right) u\left[W_{s}\left(1+r_{0}\right)+c W_{s}\left(1+r+\underline{\mu}^{H, B, e}\right)\right]\right) f(r) d r \\
& -\int_{-\infty}^{+\infty}\left(p_{0} u\left[W_{s}\left(1+r_{0}\right)+c W_{s}\left(1+r+\underline{\mu}^{L, G, e}\right)\right]\right. \\
& \left.+\left(1-p_{0}\right) u\left[W_{s}\left(1+r_{0}\right)+c W_{s}\left(1+r+\underline{\mu}^{L, B, e}\right)\right]\right) f(r) d r .
\end{aligned}
$$

First, we have $\omega(0)=0$. For the second property, we note:

- Condition (1) of Assumption 3 is satisfied since we assume $\underline{\mu}^{H, G, e} \geq \underline{\mu}^{L, G, e}$ and $\underline{\mu}^{H, B, e} \geq \underline{\mu}^{L, B, e}$, which implies $\forall r, X>Y$, and $Z>T$.

- Condition (2) is satisfied since $\underline{\mu}^{H, G, e}, \underline{\mu}^{L, G, e}, \underline{\mu}^{H, B, e}, \underline{\mu}^{L, B, e}$ do not depend on c, which implies that

$$
\partial M^{c, H, G, e^{*}} / \partial c=\partial M^{c, L, G, e^{*}} / \partial c=\partial M^{c, H, G, e^{*}} / \partial c=\partial M^{c, L, B, e^{*}} / \partial c=0
$$

- Condition (3) is satisfied since $C_{e}()=$.0 .

\section{PROOF OF EXAMPLE 3}

Assume that the probability distributions of $M^{j, k, m}$ are Gaussian $N\left(a^{j, k, m}, \sigma\right)$ with $\mu^{j, k, m} \in\left[\underline{\mu}^{j, k, m}, \bar{\mu}^{j, k, m}\right]$

Suppose that the manager's ambiguity index $C_{m}$ corresponds to the Log entropy (see footnote 7) with respect to respectively given Lognormal distributions $N\left(a_{0}^{j, k, m}, \sigma\right)$ of $M_{0}^{j, k, m}$ with $\mu_{0}^{j, k, m} \in\left[\underline{\mu}^{j, k, m}, \bar{\mu}^{j, k, m}\right]$. The standard probability calculus yields:

$$
\begin{gathered}
C_{m}\left(P_{R, M^{j, k}}\right)=\xi R\left(M^{j, k, m}, M_{0}^{j, k, m}\right)=\xi E_{M_{0}^{j, k, m}}\left[\left(\frac{d M^{j, k, m}}{d M_{0}^{j, k, m}}\right) \log \left(\frac{d M^{j, k, m}}{d M_{0}^{j, k, m}}\right)\right] \\
=\xi\left[\frac{1}{2}\left(\frac{\mu^{j, k, m}-\mu_{0}^{j, k, m}}{\sigma}\right)^{2}\right] .
\end{gathered}
$$

Using Lemma 2, the manager's initial expected wealth when the contribution $c$ is null is defined by equation (23):

$$
\begin{aligned}
V^{0, j, k}= & \operatorname{Min}_{P_{R, M}^{j, k, m} \in \Delta_{m}}\left(W_{d} E\left[1+R+M^{j, k, m}\right]+C_{m}\left(P_{R, M^{j, k}}\right)\right) \\
& =W_{d}\left[1+\mu^{0, j, k, m}, *\right]+\xi\left[\frac{1}{2}\left(\frac{\mu^{0, j, k, m, *}-\mu_{0}^{j, k, m}}{\sigma}\right)^{2}\right],
\end{aligned}
$$

which leads to (first-order condition):

$$
\mu^{0, j, k, m, *}=\mu_{0}^{j, k, m}-W_{d} \sigma^{2} / \xi
$$


The manager's initial expected wealth for any given contribution $c$ is defined from:

$$
\begin{array}{r}
V^{c, j, k}=\operatorname{Min}_{P_{R, M} j, k, m_{\in} \in M_{m}}\left(\left(W_{d}-c W_{s}\right) E\left[\left(1+R+M^{j, k, m}\right)\right]+C_{m}\left(P_{R, M^{j, k}}\right)\right) \\
=\left(W_{d}-c W_{s}\right)\left[1+\mu^{c, j, k, m, *}\right]+\xi\left[\frac{1}{2}\left(\frac{\mu^{c, j, k, m, *}-\mu_{0}^{j, k, m}}{\sigma}\right)^{2}\right],
\end{array}
$$

which leads to (first-order condition):

$$
\mu^{c, j, k, m, *}=\mu_{0}^{j, k, m}-\left(W_{d}-c W_{s}\right) \sigma^{2} / \xi .
$$

Note that we have $\mu^{c, j, k, m, *} \geq \mu_{0}^{j, k, m}$ and that $\mu^{c, j, k, m, *}$ is increasing with respect to the contribution $c$.

Both intuitively and in practice, this means for example that the manager increases the contribution given to the employee if the minimal expected return itself increases.

Examine now the maximum compensation ${ }^{\prime} c_{k}$ that can be granted by the manager. This is the solution $c$ of:

$$
\begin{gathered}
\left(W_{d}-c W_{s}\right)\left[1+\mu^{c, H, k, m, *}\right]+\xi\left[\frac{1}{2}\left(\frac{\mu^{c, H, k, m, *}-\mu_{0}^{H, k, m}}{\sigma}\right)^{2}\right] \\
=W_{d}\left[1+\mu^{0, L, k, m}, *\right]+\xi\left[\frac{1}{2}\left(\frac{\mu^{0, L, k, m, *}-\mu_{0}^{L, k, m}}{\sigma}\right)^{2}\right] .
\end{gathered}
$$

Substituting Relations (24) and (26) in Equation (27), and denoting $X=W_{d}-c W_{s}$, we get a polynomial equation with respect to $X$, namely:

$$
A X^{2}+B X+C=0
$$

with

$$
A=\sigma^{2} / 2 \xi ; B=-\left(1+\mu_{0}^{H, k, m}\right) ; C=W_{d}\left[1+\mu_{0}^{L, k, m}\right]-\left(W_{d}^{2} \sigma^{2} / 2 \xi\right)
$$

We deduce that the maximum compensation $c_{k}$ is equal to

$$
\begin{gathered}
\hat{c}_{k}=\frac{W_{d}-X}{W_{s}} \text { with } \\
X=\frac{\left(1+\mu_{0}^{H, k, m}\right)+\sqrt{\left(1+\mu_{0}^{H, k, m}\right)^{2}-2\left(\sigma^{2} / \xi\right)\left(W_{d}\left[1+\mu_{0}^{L, k, m}\right]-\left(W_{d}^{2} \sigma^{2} / 2 \xi\right)\right)}}{\left(\sigma^{2} / \xi\right)} .
\end{gathered}
$$

Note that:

1) 


$$
C_{m}\left(P_{R, M^{c, j, k, *}}\right)=\xi\left[\frac{1}{2}\left(\frac{\mu^{c, H, k, m, *}-\mu_{0}^{H, k, m}}{\sigma}\right)^{2}\right]=\left(\sigma^{2} / 2 \xi\right)\left(W_{d}-c W_{s}\right)^{2} .
$$

is decreasing with respect to the contribution $c$ (recall that $W_{d}-c W_{s} \geq 0$ ).

2) We also have:

$$
\left(W_{d}-c W_{s}\right)\left[1+\mu^{c, H, k, m, *}\right]=\left(W_{d}-c W_{s}\right)\left[1+\mu_{0}^{H, k, m}-\left(W_{d}-c W_{s}\right) \sigma^{2} / \xi\right] .
$$

Therefore, we deduce that if, for example $\xi \geq \frac{\sigma^{2} W_{d}}{\left(1+\mu_{0}^{H, k, m}\right)}$, the function $\left(W_{d}-c W_{s}\right)\left[1+\mu^{c, H, k, m, *}\right]+\xi\left[\frac{1}{2}\left(\frac{\mu^{c, H, k, m, *}-\mu_{0}^{H, k, m}}{\sigma}\right)^{2}\right]$ is decreasing with respect to $c$. Thus, using (1), $\omega(c)$ is itself decreasing, which corresponds exactly to the assumption of Proposition 3. This means that, if the aversion to ambiguity is sufficiently high, then we find the same behavior as in the no ambiguity case.

\section{PROOF OF PROPOSITION 4}

A Perfect Subgame Nash Equilibrium $\left(V^{c, H}, U^{c, H}\right)$, with $c>0$, is characterized by the following conditions:

- The manager plays $c>0$ if conditions $V^{c, H}>V^{0, L}$ and $V^{c, H} \geq 0$ are satisfied.

- The employee chooses the level of effort $k=H$ if $U^{c, H}>U^{c, L}$ and $U^{c, H} \geq 0$.

* First, according to Assumption 2, when $c=0$, the expected utility of the employee is strictly positive when they choose the level of effort $j=L$, and strictly greater than the value obtained when they choose the level of effort $j=H$, because $\psi\left(e^{H}\right)>\psi\left(e^{L}\right)>0$.

Thus, we can conclude that the employee's participation in the firm is optimal.

Thus, $U^{c, H} \geq U^{c, L}$ and $U^{c, L} \geq U^{0, L}$ (see Assumption 2) implies $U^{c, H} \geq 0$.

* Second, the manager's exit cannot correspond to an equilibrium since $V^{0, L}$ is always possible, as stated in the first point, and it is strictly positive. Thus, condition $V^{c, H} \geq V^{0, L}$ implies condition $V^{c, H} \geq 0$.

* Third, with $\quad \omega\left(c^{*}\right)=\psi\left(e^{H}\right)-\psi\left(e^{L}\right) \quad$ and Proposition 2, condition $\omega^{-1}\left[\psi\left(e^{H}\right)-\psi\left(e^{L}\right)\right] \leq \mathcal{C} k, \forall k=G, B$, implies $c^{*} \leq \mathcal{C} \%$.

The value $\mathcal{C}_{k}$ is the maximum compensation that can be granted by the manager. Above $\mathcal{C}_{k}$, employee ownership becomes too costly for the manager.

Indeed, the manager grants company stock if $V^{c^{*}, H, k} \geq V^{0, L, k}$. Recall that $V^{c, H, k}$ is decreasing with respect to $c$ and that the value of $\mathcal{C}_{k}$ is characterized by $V^{c_{k}, H, k}=V^{0, L, k}$. It follows that the participation condition of the manager $V^{c^{*}, H, k} \geq V^{0, L, k}$ for any $k$ necessitates $c^{*} \leq \mathcal{C}_{k}$. 
* Fourth, $U^{c, H} \geq U^{c, L}$ is equivalent to $\omega(c) \geq \psi\left(e^{H}\right)-\psi\left(e^{L}\right)$.

This characterizes a Perfect Subgame Nash Equilibrium with a positive $c^{e}$, with equality in the preceding relation. 